\title{
Metastatic Pulmonary Calcification in a Hemodialysis Patient after Renal Transplantation
}

Vicente R*, Santos $\mathbf{R}$ and Amoedo $M$

Nephrology Department, Hospital do Espírito Santo de Évora, Évora, Portugal

*Corresponding author: Vicente R, Nephrology Department. Hospital do Espírito Santo de Évora, Évora. Largo do Sr. da Pobreza, 7000-811 Évora, Portugal

Received: June 16, 2021; Accepted: July 13, 2021;

Published: July 20, 2021

\section{Clinical Image}

This is the case of a 64-year-old man, on renal replacement therapy since 2008, due to autosomal dominant polycystic kidney disease. The patient was on peritoneal dialysis from 2008 to 2016, when he underwent renal transplantation. Transplant duration was less than a month due to acute vascular rejection. Since then, he is on hemodialysis. A few months after transplantation, it was incidentally identified confluent bilateral opacities, more prominent

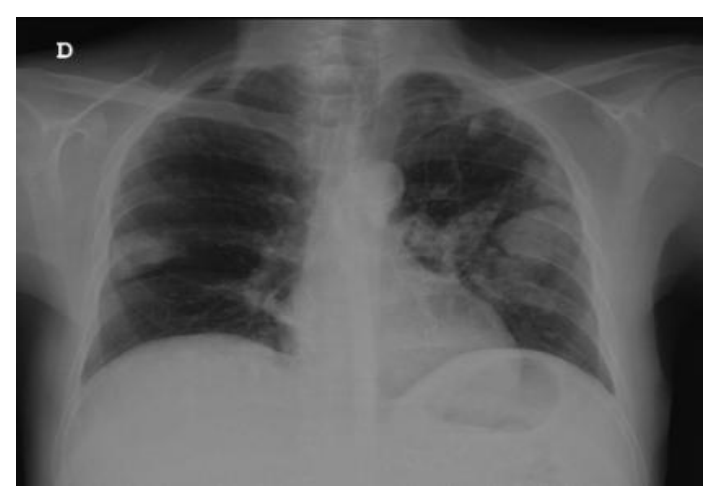

Figure 1: Chest X-ray in posteroanterior view showing confluent bilateral opacities more evident on the left lung.

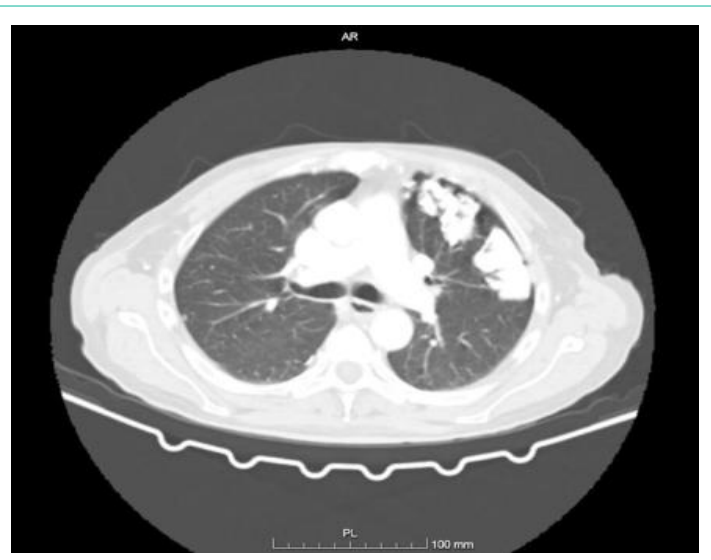

Figure 2: Computed tomography showing parenchymatous densification areas partially calcified.

on the left lung in a routine X-ray (Figure 1). The patient had made a chest radiography in 2015 without any changes at that time. The CT scan showed parenchymatous densification areas, partially calcified, in both lungs (Figure 2). The patient also developed secondary hyperparathyroidism refractory to medical therapy but refused surgery. Nevertheless, the lesions had a slow progression until the present time. 